\title{
Sexual Violence Extends Beyond Conflict
}

\section{BY KARIN WACHTER}

THROUGHOUT HISTORY, sexual violence has been accepted as an unfortunate but unavoidable aspect of warfare, and only recently has the seriousness and enormity of the problem gained the attention of the international humanitarian community, criminal courts, the media and academic researchers. Similarly, it is only recently that policies have been developed, and resources dedicated, to address the consequences of sexual violence during conflict and, in vague terms, attempt to prevent it. However, to address sexual violence only during humanitarian emergencies is to ignore the endemic nature of violence against women on a global scale and neglect its adverse impact on the development of a country. ${ }^{1}$

\section{- Rape as an obstacle to development}

IT IS NOW WIDELY ACGEPTED that sexual violence escalates dramatically during times of instability, insecurity, conflict and displacement. The systematic use of rape has many purposes, including control and domination of target populations based on ethnicity, political affiliation or geographical location. ${ }^{2}$

Survivors of sexual violence are exposed to debilitating short- and long-term social, physical, emotional and economic consequences. A common scenario of how these consequences are experienced is that after being gang-raped and impregnated, a woman is often abandoned by her husband and left to care for their children. She can no longer rely on the support of her community, some of whom think of her as - "unclean." She often feels sick and, due to a debilitating sense

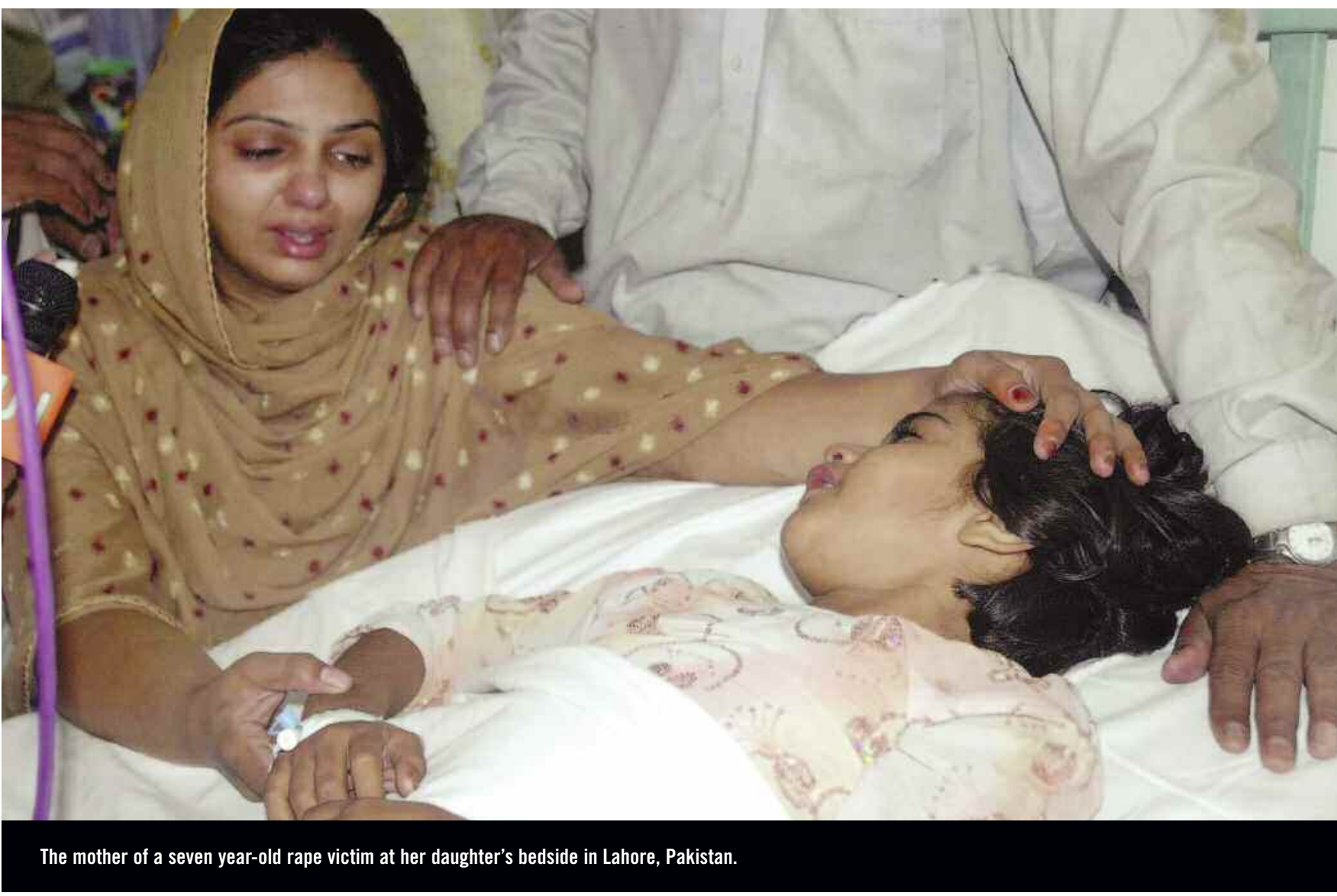


NUMBER OF WOMEN AND GIRLS RECEIVING SERVICES THROUGH IRC SEXUAL ASSAULT AND REFERRAL CENTERS IN SIERRA LEONE FROM 2002-2009

\begin{tabular}{|c|c|c|c|c|c|c|c|c|}
\hline \multicolumn{6}{|c|}{ YEAR INCIDENT WAS REPORTED } & \multicolumn{3}{|c|}{ Jan-April, } \\
\hline $2002^{3}$ & 2003 & 2004 & 2005 & 2006 & 2007 & 2008 & 2009 & TOTAL \\
\hline 3 & 417 & 523 & 714 & 703 & 805 & 758 & 214 & 4,134 \\
\hline
\end{tabular}

of fear and shame, she is limited in her ability to participate in community events. Nevertheless, she forces herself to return to the fields where she was attacked in order to feed her children. She can no longer pay her children's school fees; she had hoped they would go further in school than she did.

Take the example of this one woman and multiply her by 10,000 , or 200,000 , or 800,000 , as one can do in the Democratic Republic of Congo, Bosnia, East Timor, Rwanda, Liberia, or Darfur. The consequences of sexual violence are devastating for the individual and far-reaching for the family, community and society as a whole. Sexual violence destroys the fabric of a community in a way that few weapons can by tearing apart families, generating fear and mistrust, and creating a public health crisis.

Sexual violence also further diminishes the status of women and girls and their perceived value within their communities, which in turn contributes to a cycle of violence and vulnerability. One example of this is illustrated by the rates of women and girls continuing to seek assistance for the assault, exploitation and discrimination they continue to experience after the fighting ends.

What was traditionally considered a private matter, or an inevitable part of a women's life, is now understood as an obstacle to development. The experience and threat of violence, especially in an environment that does not promote gender equality, limits women's potential to be active and contributing participants in society. To assume that violence against women and girls starts and ends with war ignores the fact that it inhibits a country's progress and development. ${ }^{4}$

\section{Smoke and mirrors: What data are really needed?}

THERE IS A SHARED GOAL in the international community to improve data collection and analysis in the field of humanitarian assistance and post-conflict policy and practice. But when it comes to the subject of violence against women and girls, a meaningful debate on the learning priorities, purpose and modalities of data collection is too often obscured by an overwhelming demand for simply "more data." The call for
- reporting mechanisms or population-based prevalence data on violence against women should not be, by itself, the new definition of action. Considerable progress has already been made to demonstrate clearly that women and girls are targeted for, and suffer the impacts of violence. 5 Today's challenge, rather, is to focus data collection on contributing to a nascent but growing body of evidence on what interventions effectively address women's needs, reduces their vulnerability to violence and improves their overall status.

One such research initiative has been undertaken by the International Rescue Committee (IRC), which has invested resources into developing practical systems to monitor the quantity and quality of services provided to survivors of sexual violence. The initiative was aimed at demonstrating a causal link between services provided and a change in the psychological well-being and social function of clients.

In the Democratic Republic of Congo, Dr. Paul Bolton of John Hopkins University, and the IRC collaborated to develop a tool that seeks to measure change in the psychological and social well-being of survivors based on their own priorities. The tool measures the extent to which clients are able to carry out everyday activities important to them, as well as locallydescribed mental health problems. The tool is administered by the counselor before services are provided, at varying times during services, and upon discharge. 6

Baseline data from approximately 300 survivors of sexual violence seeking services was collected in 2008, revealing a high level of symptom severity and dysfunction. All 300 clients were then provided with a variety of basic services based on their individual needs and requests (i.e. basic counseling, referrals to medical and legal services, family counseling and group activities). Preliminary analysis of data collected upon client discharge indicates that both depression and function indicators showed improvement. ${ }^{7}$

Upon further analysis, the IRC intends to continue to use

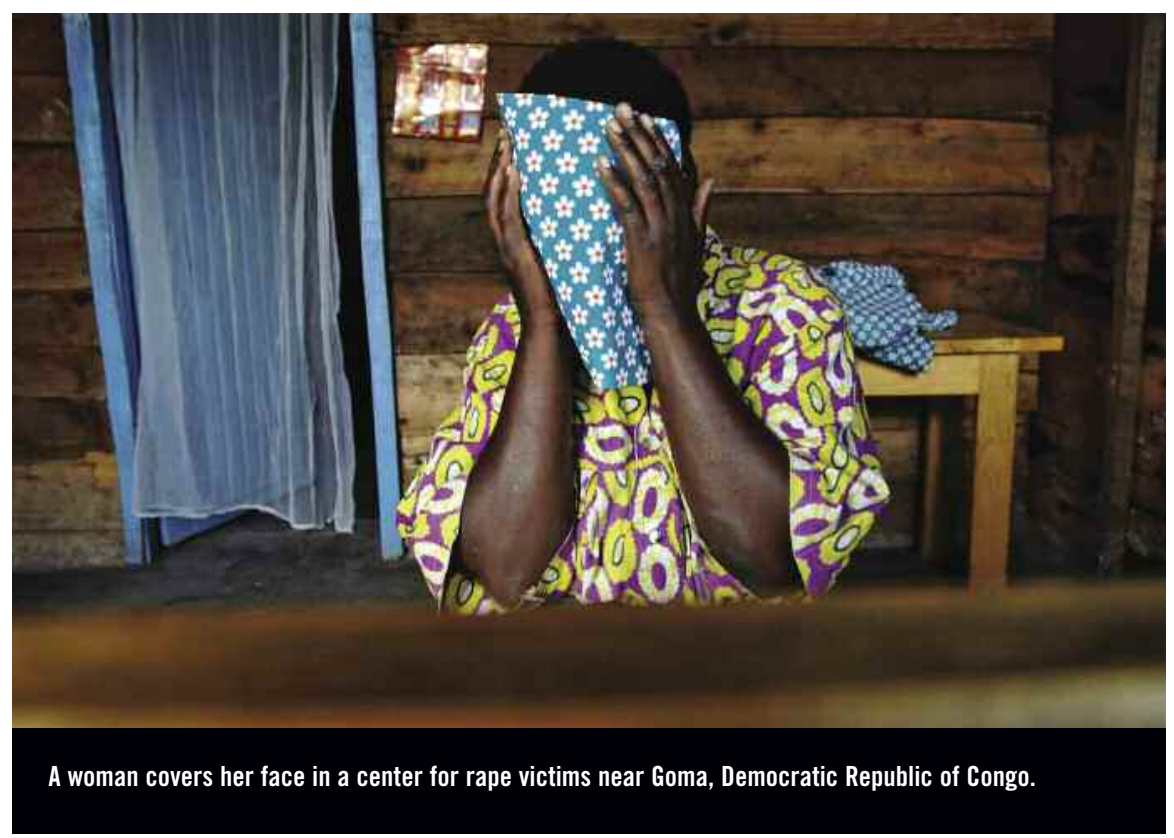


the tool to complement program monitoring. The next phase of research would focus on producing data that would allow the IRC to make the causal link between specifically developed services and program impact. This would include testing new approaches to service provision and measuring their impact, something which has yet to be done in eastern DRC.

This research initiative is part of a program that has been serving and advocating for thousands of conflict-affected Congolese women and girls since 2002. The intent is to offer this process and learning to the wider humanitarian and development community. It is just one contribution to a growing list of learning priorities that requires continuous analysis and careful scrutiny.

In conclusion, experience has demonstrated that practitioners, researchers and policy makers need to promote data collection within the context of taking action to concretely improve the lives of women and girls. These efforts must focus on producing a practical assessment of those actions, evaluation of their effect and strategy for how to take them to scale.

Karin Wachter is a Gender-Based Violence Technical Advisor with the International Rescue Committee.

www.theirc.org

\section{Endnotes}

1 Secretary-General's In-Depth Study on All Forms of Violence Against Women, pg. 22, July, 2006.

2 See the IASC Guidelines for Gender-Based Violence Interventions in Humanitarian Settings, September, 2005. Over a thousand survivors of sexual violence (women and girls) received services through IRC's program in the Central African Republic over seven months in 2007. One incident of violence reported went back as far as 1983, but the majority reported spanned the period of instability, fighting and mass displacement between 2002 and 2007.

3 In January 2002, the war in Sierra Leone was declared over. By 2004, the disarmament process was complete.

4 Data shows that discriminatory practices against women prevail in almost all parts of the world. Progress of the World's Women 2008/2009, pg. 72. http://www.unifem.org/progress/2008/media/POWW08_Report_Full_Text.pdf

"A wide range of research highlights the serious social and civil consequences of violence against women. In many societies, women provide emotional and financial support for families and communities. Studies have shown that violence and the social stigma of violence negatively affect the ability of women and girls to participate fully in and contribute to their communities." (pg. 7) International Violence Against Women: U.S. Response and Policy Issues, Congressional Research Service, March 31, 2008. http://www.fas.org/sgp/crs/misc/RL34438.pdf

5 In addition to reports by Human Rights Watch, Amnesty International and DCAF, see work by the World Health Organization and collaborators on bringing together research conducted in over ten countries that highlights the prevalence of violence against women across countries. Ellsberg, Mary and Heise, Lori, Researching Violence Against Women: A Practical Guide for Researchers and Activists, Washington DC, United States: WHO, PATH; 2005.

6 Based on an abstract written by Sarah Mosely (IRC), Karin Wachter (IRC) and Paul Bolton (John Hopkins University), March, 2009.

7 Ibid
Botтom-Up State Building

continued from page 28

presence and more access to basic services such as water and sanitation, better housing infrastructure and decent access to justice and the rule of law. Building resilience in these communities to reduce the probability of the viral spread of violence experienced during the post-election period can be achieved through broader development policies at the level of the community. As long as there is abject poverty, increasing levels of inequitable growth, high unemployment, and limited institutional presence, poor communities will continue to be breeding grounds for surges of violence, such as the one experienced during the post-election period.

\section{Policy orientations}

SOME BASIC INSIGHTS can be gleaned from these experiences. First and foremost, there is a strong relationship between state fragility and high levels of violence. The incapacity of the state to ensure basic security of its citizens undermines governance and creates opportunities for nonstate criminal groups to supplant the state. Thus, reducing violence is an essential aspect of reducing fragility overall.

Communities represent a key entry point for these efforts. Citizens' confidence in the security and justice systems as the principal means for dispute resolution creates an important opportunity for interventions in those sectors.

Beyond basic security, the root causes of violence and fragility, that is, the social and economic marginalization residents face, must be addressed.Promising approaches include World Bank Community Driven Development processes, which can serve as a forum for community reconciliation and consensus building on local development. Also, support for basic service provision in violence hot spots can be a means to bring the state presence back into under-governed areas, helping to rebuild state legitimacy in violence-affected communities. By linking violence prevention and institutional strengthening, development institutions can go a long way toward arresting the cycle of violence and poverty that holds vulnerable communities back from sustainable development.

Erik Alda and Alys M. Willman are members of the Conflict, Crime and Violence team, Social Development Department, The World Bank. This paper has greatly benefited from the constructive comments from Alexandre Marc, Coordinator of the Conflict, Crime and Violence team.

\section{Endnotes}

1 This quote and those that follow are taken from a focus group conducted in Cité Soleil in August 2008 by the Interuniversity Institute for Research and Development (INURED).

2 Fieldwork is part of a global study of urban violence being conducted by the Conflict, Crime and Violence team (SDV) to be published later this year.

3 http://www.cipev.org/home.asp 